\title{
EDITORIAL
}

\section{Good management is hard, but someone has to do it (and here are some suggestions)}

This 2nd edition of Journal of Management and Organisation (JMO) for 2018 offers a range of papers that present, tackle or even offer solutions to some of the difficult problems that challenge the supposedly 'soft' discipline of management. Although we are well acquainted with terms such as 'turbulence' and living in a 'dynamic work environment', the reality is that managers are increasingly operating in a world where they are no longer expected to simply resolve previously experienced problems. Managers of the 21st Century are now expected to innovate to solve unexpected and completely new problems. As the papers in this edition of JMO suggest, many of these problems are not actually new - the fact is that management is simply having to face problems that once could be hidden or even ignored.

Each paper presented here will thus bring into the light a problem, from the complicated but perhaps low uncertainty (tame) to the critical problems when difficult or important decisions must be made. There are even some that may fit that black box category of being a 'wicked problem'.

Problem-solving skills are at the heart of much of what we teach in management education at both undergraduate and postgraduate levels. It was Rittel and Webber (1973) who suggested that problems could be conceptualised, through reference to the notions of certainty and complexity, as either tame, crisis or wicked. Tame problems are thus ones in which both the causes and solutions are already known, so they present a limited uncertainty. Although they may be complex, they can be resolved. This is the predictable type of problem-solving many of us deal with almost exclusively in teaching our management courses, because they are problems that are amenable to command and control solutions of management.

The second type of problems, crisis problems, are also ones postgraduate students, in particular, may be taught about as part of their education. These are time pressured, they require urgent action and they may have serious consequences. Although they are often on a larger scale than tame problems, they are still highly amenable to management solutions (Chilingerian \& Savage, 2005).

In contrast, wicked problems are complex, often intractable and always without an obvious solution. These are the problems that are resistant to traditional management solutions. In addition to being intractable and/or novel, they are also often embedded in contradictory and volatile environments (Kolko, 2012). The term 'wicked' is not because they are 'bad' or even 'evil', but it is because they present problems of a darker or unsolvable nature (West Churchman, 1967). Within the organisational context, these are often social problems or ones that arise as the product of complex systems in which the solutions to one problem provide no insight into another or in which solutions are at best partial, or may even create further problems (Juzwishin \& Bond, 2012). This means that wicked problems require multiple partial solutions. An important corollary that many researchers add is that solving critical and wicked problems needs more than just management; it needs 'good' management and leadership (Hutchinson et al, 2015).

With this background in mind, we begin this edition of $J M O$ with a paper that presents a problem that may be close to home for many readers of this journal, the notion of the fear of academic failure. This is not a lightweight problem, as the fear of failure is often compounded by being a problem that no one speaks of. It is this 'hidden' and undiscussed nature of failure that makes it even stronger. What is perhaps most important is that it is also a fear that is an increasing feature of working (let alone academic) life.

It is for this reason that this first paper is a specially invited one from Marissa Edwards and noted academic luminary Professor Neal Ashkanasy. Their paper confronts the issue head-on with the apt 
title of 'Emotions and Failure in Academic Life: Normalising the Experience and Building Resilience'. Edwards and Ashkanasy present a compelling argument as to the need for conversations about the failure to be normalised. Seeing the problem as one focussed on dealing with the damaging consequences, rather than the causes of them, moves fear of failure from being a crisis or even a wicked problem to hopefully being a tame one. This is a paper that offers hope in that it offers the management practical ways to build resilience in the coming generations of young scholars.

The notion of reframing a problem, in this case the notion of failure, is a key theme of many writers in the area of the problem-solving, and it pervades the papers here. Our second paper 'Capitalism as discourse: How can strategic management scholars contribute new insights and refocus debate?' by Angelina Zubac uses reframing to reexamine the strategic management literature - to find out what it does not say. Although much more of a conceptual problem, what she finds is that while economists have been inordinately influential in the study of capitalism, it is virtually a nontopic in strategic management. It is a gap that suggests a problem for management - as capitalism is the dominant form of economic activity in most Western nations but is not seen as an area for strategic management investigation. Zubac's paper is like a light shining into a dark room as she eloquently and simply suggests not only the problem but also the potential for a solution that offers greater insight for strategic management to contribute to the wider discourse on capitalism.

The link between the conceptual and practical worlds of problem identification and solving come together in our third paper. Titled 'When unforeseen events become strategic', author Mette Vinther Larsen and Jørgen Gulddahl Rasmussen present the example of cooperation between a small Danish Software Company and mining industry staff to show how continual shifts in an uncertain environment operated to constructively shape the ways in which their respective managers developed organisational strategies. While the initial cooperation was initially perceived as responding to an unforeseen problem, over time it incrementally and retrospectively became strategic. The paper provides an important insight into our wider theme of problem-solving as it focusses attention on the individual meanings and uniqueness of events when learning more about the who, what and how of strategising.

Our third paper moves us from unforeseen events and problems to the dramatic and the critical. In 'Don't mess with my company': An exploratory study of commitment profiles before and after dramatic external events', researchers Luis M. Arciniega, Natalie J. Allen and Luis González take us to Venezuela. In what they call taking 'advantage of a serendipitous opportunity', the authors tell the story of a large organisation dealing with a series of dramatic, and unexpected, political events directed specifically at them. Although many organisations would expect employee problems to arise as the direct result of such events, the authors report that the organisational commitment profiles of employees before and after these events did not show this at all. Instead, employee continuance commitment did not change and both affective and normative commitment actually increased significantly during the period of the study. These results do suggest that the traditional management view to see crises as a problem may not be quite so clear-cut.

This lesson is developed further in our fourth paper where David Brougham and Jarrod Haar examine 'Select Smart Technology, Artificial Intelligence, Robotics, and Algorithms (STARA): Employees' perceptions of our future workplace'. Again, this is a paper in which the title speaks to the problem that it addresses - in this case, the fact that while futurists commonly predict that by 2025 STARA may replace a third of jobs that exist today, the problem is that we actually know very little about how employees perceive these technological advancements. The authors developed their own measure of STARA awareness to capture the degree to which employees feel their job could be replaced by these four types of technology. What they found certainly falls outside of the scope of 'tame' problems to offer a new range of challenges but perhaps also suggests some areas of opportunity for managers of this future workforce. 
Reframing and questioning what we think we know has been very much a theme of the papers of this 2 nd edition of JMO for 2018. It is a theme that we take a step further in the fifth paper. Here authors John Han, Gil S. Jo and Jina Kang pose the challenging question of 'Is high-quality knowledge always beneficial?' Their research is centred on the areas of knowledge overlap and innovation performance within the context of technological mergers and acquisitions and they ask this question within a framework, which includes both the quantity and quality of knowledge. For those readers who follow the flow of the papers in the order we have offered here, the conceptual nature of Zubac's paper can be seen to be tested here. The fundamental assumption underlying mergers and acquisitions is often one of economic rationalisation where extra resources are seen as wasted money. However, the results of this study reveal that a high quality of overlapped knowledge has a positive effect on subsequent innovation performance, while the effect is negative for no overlapped knowledge quality. In addition, this research investigates the influence of the knowledge quantity on subsequent innovation performance. Once again, this paper suggests that reframing what was seen as a problem may in fact lead to greater insights and, at a practical management level in this paper, at least the result was improved innovation performance.

While looking at large data sets to reframe questions may yield insights that speak to some readers, others may prefer a more human story. It is for this reason our sixth paper moves to a qualitative perspective of the nexus between problem-solving and good management. In their article 'Migration: A means to create work-life balance?', Suzette Dyer, Yiran Xu and Paresha Sinha present the postmigration work-life balance or conflict experiences of 15 Chinese-born mothers living in New Zealand. Set within the wider and very topical worldwide concerns with integrating migrants, this paper identifies the complexities and nuances of the problems involved and which a diverse range of stakeholders must understand.

Although the papers in this issue have dealt with important issues, there has also been a general theme of optimism and hope that good management and leadership will at least see positive outcomes. Our seventh paper develops this further as Mohammad Jalalkamali, Mohammad Iranmanesh, Davoud Nikbin and Sunghyup Sean Hyun present 'An empirical analysis of the effects of humor on communication satisfaction and job performance in international joint ventures in Iran'. An underlying subtext of this examination of the relationships between humour (frequency and effectiveness), communication satisfaction (informational and relational) and employee job performance (task and contextual) is that something seen as normal in the social context (where it is often seen as informal and spontaneous) can make an important contribution to overcoming workplace problems. This is exactly what the authors did find, as not only did the frequency of humour produce significant positive effects on contextual and task performance but also on informational and relational communication satisfaction. Once again, reframing a situation sees the antecedents rather than the outcomes as the place to start.

Before anyone sees this as the 'Mary Poppins' ending, we have included a very down-to-earth case study as the 'story' to bookend this edition. In 'Social enterprise to social value chain: Indigenous entrepreneurship transforming the native food industry in Australia', we offer a case study from Danielle Logue, Alexandra Pitsis, Sonya Pearce and John Chelliah. It is a story of inspiration that starts from a very real and very 'wicked' problem that we see too much of in wider society and which is often hidden or unspoken in workplaces. The case study of Indigiearth begins with the founder, Sharon Winsor, trying to find scape from an abusive relationship and to provide for her family. The case study will hopefully provide inspiration and aspiration for some as it shows how Sharon turned to her knowledge of native foods and love of 'wild harvesting' from her childhood to develop a thriving business. The problems she now faces mirror many of those facing any growing business today, but, as all of the papers presented here either implicitly or explicitly have shown, the way that they are dealt with will continue to reflect the context, the nuances and the personal experiences of those making the decisions. 
The role of the manager has been shown to be one of not just responding to problems. A good manager is also very much a leader, and this sees them not just framing a problem. They also have the ability to reframe it. For critical and wicked problems, the papers presented here suggest that the management skillset required is one of open reflection, of trying and of learning. As our invited paper in particular suggests, this skillset also requires discussions about, as well as the courage to risk, failure.

The problems each of the papers here have presented genially require the manager to act as points of collective collaboration and to work creatively to search for a range of solutions that may not be certain (Head \& Alford, 2015). In summary, being a good manager is hard and requires engaging in robust conversations that may need to challenge entrenched or accepted practices and systems. This may see changes in established ways of thinking and organisational practices. The solutions offered here suggest that managers will also require humour, moral courage, and to overcome the fear of failure, but that in doing so they are not creating or being part of the problem but become part of the solution.

Tui McKeown

Editor in Chief, Journal of Management \& Organization, Australia

\section{References}

Chilingerian, J. A., \& Savage, G. T. (2005). The emerging field of International Health Care Management: an introduction. Advanced in Health Care Management, 5, 3-28.

Head, B. W., \& Alford, J. (2015). Wicked problems: Implications for public policy and management. Administration \& Society, 47(6), 711-739.

Hutchinson, M., Daly, J., Usher, K., \& Jackson, D. (2015). Leadership when there are no easy answers: Applying leader moral courage to wicked problems. Journal of Clinical Nursing, 24(21-22), 3021-3023.

Juzwishin, D., \& Bond, K. (2012). Cultivating excellence in leadership: Wicked problems and virtues. Healthcare Management Forum, 25, 161-164.

Kolko, J. (2012). Wicked problems: A Handbook \& a Call to Action. Ac4d.

Rittel, H. W. J., \& Webber, M. W. (1973). Dilemmas in a general theory of planning. Policy Science, 4, 155-169.

West Churchman C. (1967). Wicked problems. Management Science, 14, 141-142. 